\title{
A DIMENSÃO DO HORROR NO LUTO EM "O QUE FICOU PARA TRÁS”: UMA INTERPRETAÇÃO
}

\author{
THE HORROR DIMENSION OF MOURNING IN "HIS HOUSE": \\ AN INTERPRETATION
}

\author{
Giulia Mendes Gambassi ${ }^{1}$
}

\begin{abstract}
Resumo: O objetivo deste artigo é apresentar uma interpretação do filme O que ficou para trás (2020), do diretor Remi Weekes, partindo não apenas da narrativa, mas também do contexto cultural e de migração forçada dos personagens principais, Bol e Rial Majur. Nessa história dramática de perda e solicitação de refúgio, mobilizaremos a psicanálise transcultural (MORO, 2015, BINKOWSKI; BERRIEL, 2018) enquanto discurso ou perspectiva para nos voltarmos a uma análise do que entendemos como trabalho de luto dos personagens a partir da língua-cultura dinka. Enquadrado no gênero horror, o filme nos apresenta não só a trajetória de Bol e Rial no novo país e o (des)acolhimento na Inglaterra, como também suas lutas internas com o que parece ter ficado para trás, como a tradução do título nos aponta, mas que os acompanha e se reapresenta durante toda a trama. Trabalhamos a dimensão do horror no luto via o Unheimlich freudiano e a dessubjetivação daqueles que, como Bol e Rial, arriscam-se a sobreviver inscritos em novas dimensões de alteridade e de laço social.
\end{abstract}

Palavras-chave: luto; psicanálise transcultural; migração forçada.

Abstract: This article presents an interpretation of the film His house (2020), directed by Remi Weekes, focusing not only on the narrative but also in the cultural context of forced migration of the main characters, Bol and Rial Majur. In order to interpret this dramatic story of loss and asylum seeking, we will approach the movie by mobilizing transcultural psychoanalysis (MORO, 2015, BINKOWSKI; BERRIEL, 2018) as a discourse or perspective to discuss what we interpret as the characters' work of mourning in Dinka. Classified as a horror movie, His house (2020) presents not only the trajectory of Bol and Rial in England and the country's dynamic of (not) hosting refugees, but also their internal struggles with what seems to be left behind but that accompanies them throughout the entire plot. We discuss the dimension of horror in mourning from the Freudian perspective of Unheimlich, as well as from the de-subjectivation of those who, like Bol and Rial, take a chance on surviving whilst facing new dimensions of otherness and social bond.

Keywords: mourning; transcultural psychoanalysis; forced migration.

\section{INTRODUÇÃOO}

"O que há dentro das pessoas é como o que há nos rios e na mata"2 (LIENHARDT, 1951, p. 308). Esse provérbio apresenta como o povo Dinka, do Sudão do Sul, compreende a natureza humana. Na cosmovisão ocidental, via discurso psicanalítico

\footnotetext{
1 Doutoranda na Universidade Estadual de Campinas (Unicamp), Campinas, SP, Brasil. giugambassi@gmail.com.

Orcid: https://orcid.org/0000-0002-8326-8189.

${ }^{2}$ Todos as citações feitas a Lienhardt $(1951,1962)$ no corpo do texto são traduções nossas. Sempre apresentaremos em nota de rodapé o texto original. No caso desta citação, lê-se no original: "what is in a man is like what is in the rivers and the woods" (LIENHARDT, 1951, p. 308).
} 
freudo-lacaniano, poderíamos associá-lo ao Unheimlich, ao estranho-familiar, ao inquietante ou incômodo que, ao mesmo tempo em que é algo "muito conhecido" (FREUD, [1919] 2021, p. 49), "figur[a] entre o que é aterrador, que suscita medo e horror" (FREUD, [1919] 2021, p. 48). A simbiose entre natureza e humano, ilustrada por esse provérbio, só pode ser vista dessa forma a partir de nossa perspectiva cultural, socializada para ver, em separado, esses dois elementos. Ou seja, para os Dinka, os animais e outros entes fazem parte da simbolização da alteridade: um constitui o outro; já em nossa visão sociocultural não há, em geral, relação de alteridade com a natureza: o outro é o humano. É essa compreensão do homem que possibilita a construção da figura do apeth $^{3}$ nessa cultura (LIENHARDT, 1951), central - junto ao contexto de migração forçada - para a análise do filme $O$ que ficou para trás (His house, 2020), que aqui apresentamos.

Enquadrado no gênero horror, O que ficou para trás (2020) retrata o percurso de migração do casal Bol e Rial. Na cena de abertura do filme, vemos um homem (Bol) carregando uma criança (Nyagak) no que se revela ser um trajeto de fuga do Sudão do Sul em direção à Europa. Em seguida, vemos que o homem e a criança estão acompanhados por uma mulher (Rial), que abraça Nyagak e diz que irá protegê-la. Durante o trajeto de barco pelo Mediterrâneo, Nyagak se afoga e a partir daí temos contato com o processo de (des)acolhimento ${ }^{4}$ do casal na Inglaterra, seguido pela apresentação de outras dimensões de "verdade" nessa narrativa pouco linear. Entretanto, o que parece ser apenas outro filme que aqui e ali apresenta figuras que podem causar medo, baseado nas cada vez mais frequentes migrações forçadas, revela-se como um caminho na línguacultura ${ }^{5}$ Dinka para lidar com o trauma que levou à fuga do país, assim como para realizar os trabalhos de luto de alguns objetos perdidos nessa dinâmica, dentre eles, Nyagak.

Neste artigo, pretendemos, então, apresentar uma leitura para o modo como o luto é praticado no enredo, acompanhados pela repetição do trauma que Rial não consegue não lembrar e partindo de um ponto de vista psicanalítico e filosófico. Feita a apresentação teórico-metodológica, na seção $O$ povo Dinka, o apeth $e$ a irrupção do trauma: caminhos para o luto começaremos por trazer o contexto cultural dos Dinka, povo do qual Bol, Rial e Nyagak fazem parte, para, a partir da figura do apeth e de seu valor simbólico, introduzirmos a questão do luto e como ela será trabalhada neste artigo. Em seguida, em $O$ que (não) ficou para trás: trabalhos de luto, traremos algumas interpretações de possíveis trabalhos de luto realizados pelos personagens, tanto via psicanálise freudo-lacaniana quanto via desconstrução derridiana. Em tempo, reconhecendo a potência do material analisado para diversas leituras e trabalhos metodológicos, apontamos que não será possível, nesta ocasião, apresentar uma análise discursiva da materialidade linguística de alguns excertos do filme, mas deixaremos apontado, aqui e ali, caminhos possíveis para fazê-lo.

\footnotetext{
${ }^{3}$ Figura espectral e/ou bruxo da noite que será apresentada em $O$ povo Dinka, o apeth e a irrupção do trauma: caminhos para o luto, neste artigo.

${ }^{4}$ A proposição de (des)acolhimento, ou seja, que acolhe e não acolhe ao mesmo tempo, no contexto de migração forçada, está sendo discutido por Louise Hélène Pavan em sua dissertação de mestrado no Programa de Pós-Graduação em Linguística Aplicada do IEL/Unicamp.

${ }^{5} \mathrm{O}$ termo língua-cultura foi cunhado por Coracini (CORACINI; CAVALLARI, 2016; CORACINI, 2019), visando destacar que uma está entranhada na outra, não sendo dissociadas nesta perspectiva.
} 


\section{TRAVESSIA TEÓRICO-METODOLÓGICA}

Apresentamos a seguir o que vamos mobilizar enquanto suporte para o trabalho interpretativo apresentado neste artigo. Nossa travessia teórico-metodológica não se coloca como ponte entre conceitos e materialidade linguística, mas enquanto acontecimento discursivo (FOUCAULT, [1969] 2008) que se dá junto ao corpus.

\subsection{Uma interpretação psicanalítica transcultural}

Em $O$ que ficou para trás (2020), para além do horror ligado à experiência da migração forçada, tão pujante em nossa sociedade, o que é posto a assustar aqueles que assistem ao filme está ligado ao processo de tentativa de simbolização do que se coloca como sem sentido em uma cultura africana. Assim, apesar de "a tradição filosófica defin[ir] a cultura como uma espécie de corte racional que nos permite apreender o mundo" (MORO, 2015, p. 186), temos sido levados a nos voltarmos a ela como sendo uma das possibilidades de interpretar o mundo, não mais a única - ainda que isso se dê, ao menos nesse caso, como uma caracterização fantástica do que, para outros povos, é real. Aliado a isso, os movimentos diaspóricos contemporâneos têm esgarçado, cada vez mais, as regularidades discursivas a partir das quais nos inscrevemos no mundo.

Nesse âmbito, ao trabalharmos com migração, principalmente com migração forçada, em um viés que se ancora em discursos psicanalíticos, é preciso dar-se a ver com dimensões simbólicas diferentes daquelas das quais partem os estudos clássicos desse campo, ou seja, eurocentrados. Essa questão ganha mais importância na montagem de dispositivos para lidar com/analisar o que se apresenta como sofrimento psíquico (MORO, 2015, p. 186) e é cada vez mais comum termos relatos de que uma psicanálise não implicada - ao seu contexto socio-histórico-cultural - tem se mostrado insuficiente frente às diferentes urgências que se apresentam tanto na clínica quanto fora dela ${ }^{6}$. Assim, mesmo que não trabalhemos diretamente em uma clínica psicanalítica transcultural neste artigo, visto que não é o fazer terapêutico que está colocado em jogo aqui, atrevemo-nos a nos voltar a ela enquanto perspectiva, enquanto uma possibilidade discursiva psicanalítica para empreender a interpretação proposta neste artigo.

Acreditamos que essa seja uma forma interessante de ler o discurso psicanalítico e que será mobilizada aqui, visto que

[...] se nossa racionalidade ocidental tende a nos orientar a um constante movimento centrípeto, insistindo em apenas uma dimensão dos fenômenos através de sua decodificação científica, o confronto com outras racionalidades e discursos - como é o caso em espaços de encontro transcultural - nos remete a sociedades que seriam, conforme Nathan e Stengers, de universos múltiplos (BINKOWSKI; BERRIEL, 2018, p. 93).

Nesse sentido, ainda que não apresentemos estudos de caso neste artigo, as travessias conscientes e inconscientes dos personagens Rial e Bol também parecem remeter à "tensão da alteridade [que] habita no [...] hiato entre singularidade e cultura, sociedade e política" (BINKOWSKI; BERRIEL, 2018, p. 98). As possibilidades de realidade construídas pelo povo Dinka e trazidas à baila no filme poderiam facilmente ser patologizadas em uma leitura mais tradicionalista dos discursos psi, o que, acreditamos, levaria a uma maior dificuldade de reestabelecimento do laço social - processo esse muito caro a sujeitos em deslocamento/migração. Essa tendência à patologização poderia, talvez, ser justificada pelo que o próprio Freud ([1917] 1996) nos diz acerca da

\footnotetext{
${ }^{6}$ Um estudo recente que se volta detalhadamente à constituição de uma "nova" clínica perante a realidade dos que se colocaram a serem escutados é o de Kantz e Dunker (2020).
} 
melancolia: "[e]m algumas pessoas, as mesmas influências produzem melancolia em vez de luto; por conseguinte, suspeitamos de que essas pessoas possuem uma disposição patológica" (FREUD, [1917] 1996, p. 249, grifo nosso). Assim, por mais abertos que estejamos ao outro ou à escuta desse outro, nossas lentes culturais podem nos levar a caminhos interpretativos dessa ordem, por acreditarmos que o que é muito diferente de nós ou do que estamos habituados só poderia indicar alguma patologia. Nesse sentido, a partir da nossa leitura de mundo, pensar que uma pessoa que tem alucinações com fantasmas e bruxos possui uma "disposição patológica", acaba por levar o profissional que a escuta a uma direção de tratamento que a aliena a uma regularidade discursiva da qual não faz parte ${ }^{7}$.

Dessa forma, alinhamo-nos ao que Moro (2015) propõe como cultura para podermos trabalhar com o material mencionado, compreendendo que é por ela que interpretamos as diversas experiências dos sujeitos, tornando possível ler os acontecimentos - com seu sentido e não sentido -, a partir de "inferências ontológicas (a natureza dos seres e das coisas)" e "de causalidade" (MORO, 2015, p. 186). Nesse âmbito, voltando-nos ao contexto do filme, destaca-se que

[a] distinção entre o que é causado naturalmente e o que tem causas sobrenaturais não existe no pensamento social dinka. Entretanto, a divisão cosmológica entre o que é dos homens e o que é dos poderes é, com efeito e respectivamente, a mesma separação entre o que os dinka conseguem controlar em sua experiência de mundo e o que não conseguem controlar (DINIZ, 2011, p. 201).

Assim, enquanto as lentes de uma psicanálise menos apta aos diversos enquadres e situações transculturais poderiam dar um nome ocidental demais a algo que talvez tenha mais a ver com o "modo de elaborar, dar sentido e modificar [a] alteração que concerne [ao sujeito ali analisado]", o que aqui chamamos de perspectiva psicanalítica transcultural busca "[1] evar em conta a dimensão cultural da elaboração[,] permit[indo] diferenciar [as] inúmeras possibilidades de atribuir sentido em face de um mesmo enunciado" (MORO, 2015, p. 187). Logo, o que pretendemos neste artigo é não reproduzir a desqualificação dos referentes culturais do sujeito migrante tal qual muitas vezes é feito pela sociedade de acolhida (MORO, 2015), ou, no caso do filme, pelo sistema de acolhimento inglês ${ }^{8}$. Trazemos, então, o contexto linguístico-cultural dos personagens para interpretar a dimensão do horror presente nos trabalhos de luto por nós apontados no longa.

\subsection{Uma perspectiva discursivo-desconstrutiva}

Buscando não nos apegarmos demais a ficções teóricas, o que empreendemos com nossa interpretação é trazer à baila efeitos de sentido que são provocados considerando não apenas o contexto narrativo, mas também a psicanálise transcultural aliada ao que Coracini (2019) chama de perspectiva discursivo-desconstrutiva. Esse "olhar filosófico" proposto pela autora, apoia-se na visão discursiva foucaultiana, na desconstrução

\footnotetext{
7 Parte dos argumentos que apresento aqui são reflexo das minhas anotações do curso Imigração $e$ psicanálise: perspectivas clínico-políticas, oferecido pelo Instituto Sedes Sapientae no primeiro semestre de 2021.

${ }^{8}$ Na primeira cena em que vemos a interação entre Rial, Bol e o sistema inglês, observamos um tratamento distante e que enfatiza que eles vão sair da "detenção" para uma "condicional" na casa que a eles for designada. Um dos agentes, quando ouve de Bol que ele e Rial são boas pessoas, diz que não é ele que precisa de convencimento, mas os outros com quem irão conviver. Essa necessidade de provar que são "boas pessoas" é reificada diversas vezes em diálogos do filme e parece reproduzir uma expectativa comum perante o estrangeiro e os refugiados nos diversos países a que chegam.
} 
derridiana ${ }^{9}$ frente ao pensamento dicotômico da cultura ocidental e na psicanálise freudolacaniana que, neste artigo, pelos motivos já expostos, será mobilizada num viés transcultural ${ }^{10}$. Ainda que haja pontos de desencontro entre esses autores, eles produziram um rico diálogo - boa parte das vezes crítico -, que enxergamos como potencializador de suas proposições teóricas ao longo de suas obras e como algo que traz força para os trabalhos que fazemos nessa perspectiva ${ }^{11}$.

\section{O POVO DINKA, O APETH E A IRRUPÇÃO DO TRAUMA: CAMINHOS PARA O LUTO}

A compreensão do humano tal qual apresentada no provérbio que abre este texto é o que torna possível, segundo o antropólogo que estudou por muitos anos o povo Dinka, Godfrey Lienhardt (1951, 1962, entre outros), a representação da figura do apeth:

[o] significado disso [do provérbio] é que nos rios e nas matas, escondidas, estão as criaturas que ferem os homens, logo, em cada homem estão escondidos vícios prejudiciais. É a avaliação da natureza humana feita nesse provérbio que é elaborada nas noções Dinka do apeth ${ }^{12}$ (LIENHARDT, 1951, p. 319)

Para os Dinka, o apeth seria tanto a capacidade que as pessoas têm de trazer o mal sobre elas mesmas sem que sejam necessários "feitiços, ritos, materiais mágicos ou agentes não humanos" 13 (LIENHARDT, 1951, p. 304) quanto bruxos da noite (night witches) que podem "comer" ${ }^{14}$ o outro. Ao mesmo tempo uma fantasia ${ }^{15}$ e uma realidade, o apeth é a personificação dos "apetites e [das] paixões presentes em cada homem que, se desgovernados, podem destruir qualquer lei moral"16 (LIENHARDT, 1951, p. 318). Por esse motivo, ele é "associado a criaturas deformadas e imperfeitas que, por sua própria natureza, não podem ser membros plenos da sociedade $^{17 ",}$ (LIENHARDT, 1951, p. 319).

\footnotetext{
${ }^{9} \mathrm{O}$ que mobilizamos neste artigo enquanto alinhado à desconstrução derridiana não é imaginar que o pesquisador pode desconstruir algo, mas, sim, deixar as palavras se abrirem à sua (im)possibilidade significante, à pluralidade de sentidos (CORACINI, 2019).

${ }^{10}$ Não estamos afirmando que a clínica psicanalítica transcultural se filie (apenas) à psicanálise freudolacaniana.

${ }^{11}$ É possível encontrar discussões que embasam o diálogo que fazemos entre autores como Foucault, Derrida e Lacan - ainda que haja pontos de desencontro entre os autores - em Birman e Hoffman (2017), Major (2002), Saal (1994), Derrida ([1990] 1996, [1992] 1994), entre outros. Para um aprofundamento na perspectiva discursivo-desconstrutiva, além de Coracini (2019), recomendamos a leitura de Discurso, Desconstrução e Psicanálise no campo da Linguística Aplicada: (du)elos e (des)caminhos, de Rosa, Rondelli e Peixoto (2015).

12 "The meaning of this is that in the rivers and the woods, lying concealed, are creatures which injure men, and so in every man there lie hidden injurious vices. It is the assessment of human nature made in this proverb which is elaborated in Dinka notions of apeth" (LIENHARDT, 1951, p. 319).

13 “[S]pells, rites, magical materials, or non-human agents" (LIENHARDT, 1951, p. 304).

${ }^{14}$ Explicaremos essa noção de "comer o outro" mais adiante.

${ }^{15}$ Não vamos mobilizar a compreensão psicanalítica de fantasia neste artigo, apesar de acreditarmos que seria profícua para outros pontos de análise.

16 "[A]ppetites and passions in every man which, if ungoverned, would destroy any moral law" (LIENHARDT, 1951, p. 318).

17 " [A] ssociated with deformed and imperfect creatures, who by their very nature cannot be full members of society" (LIENHARDT, 1951, p. 319).
} 


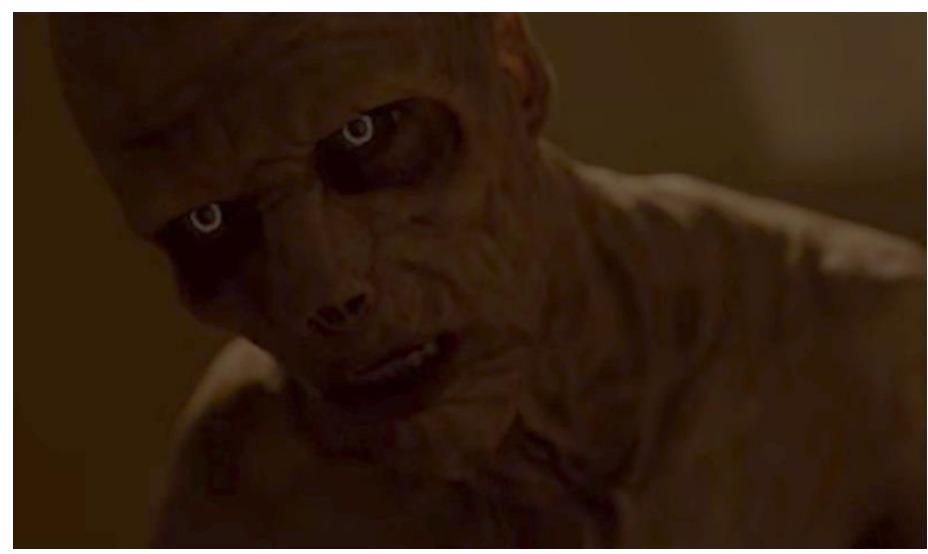

Figura 1: Apeth

Fonte: reprodução.

Mobilizar essa figura como algo do campo do horror é algo, a princípio, óbvio para esse gênero fílmico. Porém, voltando-nos mais profundamente à história do longa e às dimensões dessa figura na cultura dinka, novas possibilidades interpretativas se abrem. A narrativa principal nos coloca em contato com o trajeto de Bol e Rial, que fogem da guerra civil do Sudão do Sul. Pouco linear, como já afirmamos, ela é entrecortada por irrupções, para ambos, do que (não) ficou para trás. Uma cena que remete a isso é quando Bol, por exemplo, instalado em uma casa oferecida pelo governo britânico para que ele e Rial "provem que são dos bons"18, ouve um barulho na janela que o leva a rememorar o momento em que o barco em que estava com Rial, Nyagak e diversos outros refugiados, quebra e eles caem no mar - ouvimos gritos e outros sons que acompanham esse momento, enquanto ele tenta silenciar suas vozes.

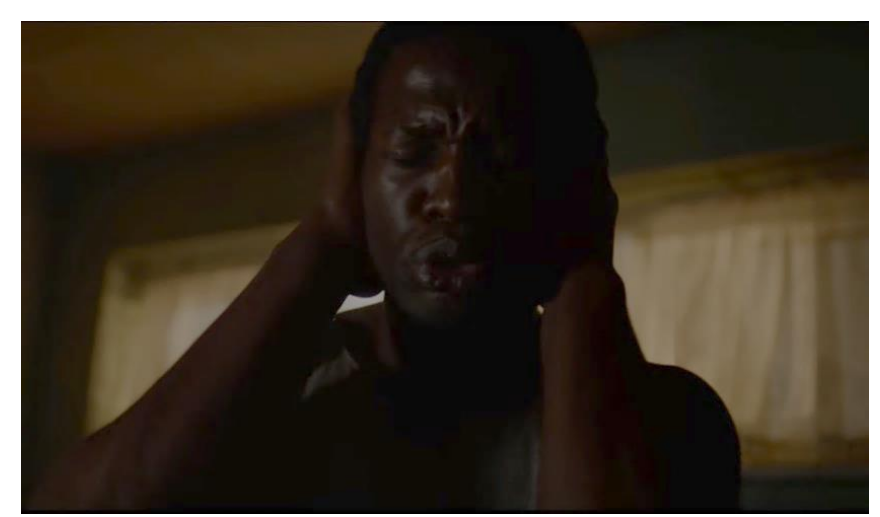

Figura 2: Bol tentando silenciar os sons do naufrágio do barco Fonte: reprodução.

Outro corte como esse é feito quando Rial está limpando a casa depois de Bol tirar o papel de parede da sala, onde, em algumas cenas, habitam o apeth e alguns fantasmas que os (per)seguem. Ao abrir a porta de um armário, Rial vê dentro dele uma camionete gradeada com Nyagak no colo de Bol.

\footnotetext{
${ }^{18}$ Como apontado na nota 6.
} 


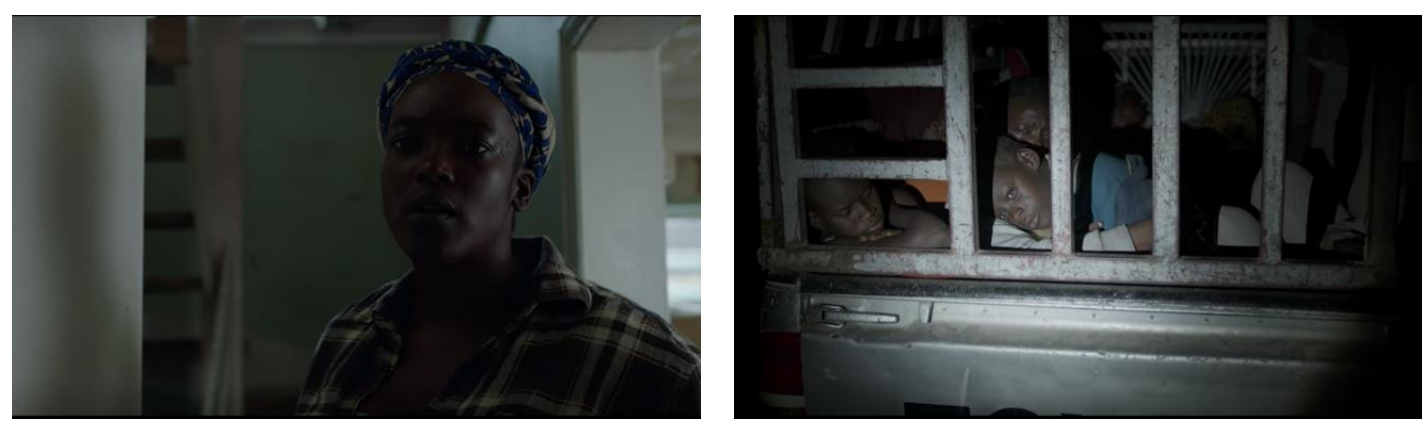

Figura 3: Rial abre a porta para uma lembrança

Fonte: reprodução

Essas janelas vão se abrindo na trama junto a irrupções do trauma por eles vivido e a um trabalho de luto que parece ser desmentido ${ }^{19}$ (IACONELLI, 2007) por Bol, até que a dimensão cultural dinka sobrepõe-se às outras verdades daquela experiência, que diriam respeito à inserção social na Inglaterra e a "deixar para trás", ou ao menos tentar, as situações terríveis pelas quais passaram. A casa - que no título em inglês do filme é o ponto principal, His house, A casa dele - vai se tornando um personagem, emulando não só o (des)acolhimento do casal no novo país, mas também a história do apeth tal qual Rial nos conta. Ela resolve falar sobre o assunto quando Bol se refere ao futuro, ao que podem fazer a partir dali. Rial, então, diz:

[m]inha mãe costumava me contar uma história. Em nosso vilarejo havia um homem honrado, mas pobre, que queria ter sua própria casa. Ele queria tanto que começou a roubar dos outros. Um dia... ele roubou de um velho que morava perto do rio. Ele não sabia que esse homem era um apeth. Um bruxo da noite. Então não tinha como o ladrão saber que quando ele construísse sua casa o apeth também viveria lá. Então, pouco tempo depois, as paredes sussurrariam os feitiços do apeth. Das sombras, os mortos viriam. O apeth não pararia até ter consumido o homem completamente.

Um apeth surgiu do oceano. Ele nos seguiu até aqui. Ele falou comigo ${ }^{20}$.

Até esse ponto da narrativa, ainda fica um pouco obscuro o motivo de o apeth ter seguido Bol e Rial se eles estavam apenas fugindo de uma guerra civil. Porém, em seguida, Rial menciona uma dívida que eles têm a pagar e que poderia fazer com que o apeth os levasse até Nyagak. Na continuidade do diálogo, parece que Rial, a partir dos dizeres de Bol, está querendo prolongar um luto que o marido diz já ter sido feito suficientemente $^{21}$. Entretanto, nas cenas finais do filme, descobrimos que, após um massacre no que parece ser uma escola, Rial sobrevive por ter se escondido dentro de um armário, sendo encontrada por Bol e por ele praticamente carregada em direção à fuga da região. Em estado de choque, Rial acompanha Bol e, tendo a oportunidade de entrar em

19 Talvez o silenciamento que Bol impõe a Rial acerca da perda de Nyagak pudesse ser lido como o desmentido do luto, que Iaconelli (2007) traz acerca do luto de mães que perderam seus bebês e que passam por situações de apagamento e diminuição de sua dor seja por profissionais da saúde ou pessoas próximas. Porém, descobrimos mais adiante que Nyagak não era filha de Rial e Bol e que tanto o sequestro da criança quanto a falha em protegê-la no trajeto ao novo país (o que torna o ato ainda mais grave perante a figura do apeth) são responsáveis pela perseguição que sofrem.

${ }^{20}$ Optamos por traduzir do inglês para o português. "My mother used to tell me a story. In our village, there was once an honorable but poor man who wanted a home of his own. He wanted it so badly, he began to steal from others. One day... he stole from an old man who lived by the river. He didn't know that this man was an apeth. A night witch. And so, the thief could not know that when he built his home the apeth, too, would live there. So, before long, the walls would whisper the spells of the apeth. From the shadows, the dead would come. The apeth would not stop... until he had consumed the man entirely.

An apeth has arisen from the ocean. It has followed us here. It spoke to me".

21 "We have grieved enough. Enough". 
um pequeno ônibus em meio ao fogo cruzado para se salvarem, recebem a notícia de que o transporte está muito cheio e que só crianças poderiam embarcar. Eis que Bol vê Nyagak sozinha e a toma em seus braços, dizendo que ela é criança, então, ele e Rial poderiam entrar no transporte e fugir. Tal como o ladrão que teve a casa tomada pelo apeth na história que nos conta a protagonista, o fato de Bol ter roubado Nyagak e "perdido" sua vida fez com que um apeth os seguisse do oceano - onde a haviam "consumido" para alcançar o que tanto desejavam - e se materializasse também em uma casa, o que se expande para uma metáfora do (não) pertencimento ${ }^{22}$ desses estrangeiros àquele local.

Até reacessar a cena traumática de um dos embates do genocídio em voga no Sudão do Sul, Rial acreditava que Nyagak era sua filha. Mas ao tentar fugir da casa assombrada e voltar para seu país, volta à cena do trauma inicial e é cercada por fantasmas daquela ocasião, descobrindo que nunca havia sido mãe. Rial percebe, só-depois, que a dívida do casal se referia ao fato de terem roubado e consumido Nyagak e isso só poderia ser sanado se Bol se deixasse "comer" pelo apeth.

\begin{abstract}
“Comer" um homem é diferente de roubar dele ( $k u a l)$. O roubo é apenas pegar algo que pertence a outra pessoa, escondê-lo e usá-lo em benefício próprio. O objeto roubado ainda existe e pode ser devolvido caso o ladrão seja descoberto. O que é comido, entretanto, está perdido, e quando essa palavra é usada, a ideia de privação injusta sofrida pela vítima é preponderante. Um homem que cobra muito por suas mercadorias não converte nada em particular para seu benefício próprio, mas sobrevive da diminuição de seu conteúdo. Então, um bruxo consome as pessoas, talvez sem ganhar nada em particular como um ladrão ganharia, mas diminui a valia daqueles que ataca. $\mathrm{O}$ roubo é um ato que nenhum Dinka tolera se conhecer o ladrão ${ }^{23}$ (LIENHARDT 1951, p. 306)
\end{abstract}

Feita essa contextualização, perguntamo-nos: de que dívida Rial falava quando contava ao marido a história do apeth se ela não se lembrava do sequestro da menina? É possível falarmos de trabalhos de luto dos personagens considerando a figura do apeth $\mathrm{e}$ o escopo narrativo? Pretendemos responder essas questões a seguir.

\title{
3. O QUE (NÃO) FICOU PARA TRÁS: TRABALHOS DE LUTO
}

Reflexões acerca do luto podem ser feitas por diversas perspectivas psicanalíticas - como bem apontam Souza e Pontes (2016), ao não só retomarem os conceitos ou as proposições base para discutirmos o tema teoricamente, mas também apresentarem um estado da arte do tema na pesquisa brasileira - e filosóficas. Aqui, iremos fazer uma interpretação mais psicanalítica, em um primeiro momento, dos trabalhos de luto que identificamos na narrativa, passando depois para uma discussão de cunho mais filosófico, a partir da noção de espectro para Derrida ([1993] 1994).

\footnotetext{
${ }^{22}$ A questão do pertencimento é algo muito imponente no filme - o que também é comum nos casos de migração forçada -, seja em relação à casa e a seu caráter "assombrado", seja pela fala de Rial quando comenta com uma médica sobre as marcas na sua pele - que identificam diferentes povos - remeterem ao fato de ela "não pertencer a lugar nenhum", ou ainda ao fato de Rial dizer a Bol algumas vezes que eles não pertencem àquele lugar (casa/Inglaterra).

23 "To 'eat' a man is different from stealing from him (kual). Theft is just taking something belonging to another, hiding it, and putting it to one's own use. The object stolen is still there to be returned if the thief is discovered. What is eaten, however, is lost, and when this word is used, the idea of the unjust deprivation suffered by the victim is uppermost. A man who charges too much for his wares does not convert to his own use any particular thing belonging to others, but lives by diminishing their substance. So a witch consumes people, perhaps gaining no particular thing himself as a thief would, but diminishing the good of those he attacks [...]. Theft is an act, which no Dinka will tolerate if he knows the thief' (LIENHARDT, 1951, p. 306).
} 
O trabalho de luto, como nomeado por Freud ([1917] 1996), diz respeito a um processo que se dá em reação à perda de um objeto, que pode ser um ente querido ou "alguma abstração que ocupou o lugar [desse] ente querido, como o país, a liberdade ou o ideal de alguém, e assim por diante" (FREUD, [1917] 1996, p. 249). Visto aqui em sua pluralidade, diversos trabalhos de luto são feitos durante toda a vida, tendo em conta que passamos por "constantes experiências de perdas que se constituem em modelos de estados psíquicos que [...] poderão ser vividos em situações semelhantes ulteriores" (CAVALCANTI et. al, 2013, p. 89). Por sua vez, no contexto migratório,

[o] fato de [o sujeito] estar distante, impossibilit[ado] de participar dos rituais e dos acontecimentos familiares e coletivos, dificulta [...] o atravessamento do luto (Baubet \& Moro, 2013). Nessas situações, o luto pode ser agravado pelo acontecimento migratório e vir a funcionar como um après-coup [só-depois] desta viagem, fazendo emergir novamente suas condições e as relações que puderam ser mantidas ou não com o parente falecido e com o país deixado (MORO, 2015, p. 188).

Em O que ficou para trás (2020), Rial e Bol parecem, a nosso ver, lidar com a morte de Nyagak de formas bem diferentes, ainda que partilhem formas de simbolizar essa perda em sua língua-cultura materna. Enquanto Rial ocupa o lugar da mãe enlutada pela perda da filha, apegando-se a quaisquer vestígios de Nyagak, Bol não a menciona, apesar de se haver com seu fantasma em suas visões dentro da casa à qual foram enviados como solicitantes de asilo. De todo modo, Rial, como colocamos anteriormente, antes de se lembrar de que Nyagak não era sua filha, mas, sim, uma criança roubada, diz a seu marido que eles têm uma dívida a pagar para poderem reaver a filha. Isso nos remete a uma leitura lacaniana desse tema, que vamos tentar sintetizar a seguir para então propor uma interpretação dessa dívida.

Para Lacan, o luto é incitado por um "rombo no real provocado por uma perda [...] intolerável ao ser humano" (LACAN, [1958-1959] 2002, p. 356). Retomando a psicose para diferenciá-la do luto, o psicanalista aponta que enquanto na foraclusão, produzida na psicose, há a rejeição de um significante fundamental no universo simbólico do sujeito (furo no simbólico), o rombo no Real oferece "o lugar em que se projeta" (LACAN, [1958-1959] 2002, p. 356) um significante faltante que também é essencial à estrutura do Outro - impotente perante essa perda, por não poder explicá-la. Assim,

[é] porque este significante encontra aí seu lugar e ao mesmo tempo não pode encontrá-lo, porque este significante não pode articular-se ao nível do Outro, que vêm, como na psicose - e é nisso que o luto se aparenta à psicose - pulular em seu lugar todas as imagens de onde surgem os fenômenos do luto e os fenômenos de primeiro plano, aqueles pelo que se manifesta não tal ou tal loucura particular, mas uma das loucuras coletivas mais essenciais da comunidade humana [...] (LACAN, [1958-1959] 2002, p. 356).

Os fenômenos do luto no caso do filme que aqui analisamos acabam por ser de um tipo de "loucura coletiva" diferente das que partilhamos enquanto brasileiros - como o destaque que damos a uma suposta ascendência europeia deixando de lado nossa história colonial para nos aproximarmos de um ideal de pureza, de branquitude, inalcançável (não só, mas de forma mais pronunciada) entre os latinos. Assim, ao mesmo tempo em que a figura do apeth vem punir, instaurando uma Lei, como se ele fosse uma representação do Outro, ela traz uma imagem essencial para tentar dar nome ou forma ao sem sentido da experiência de trauma dos personagens perante diversas situações, a saber: a quase-morte em seu país; o deslocamento que fazem, assim como os eventos a ele subsumidos; e os trabalhos de luto no que se refere à morte de Nyagak, à imagem que Rial tinha de Bol (frustrada tanto por seu desejo de se tornar igual ao ingleses quanto por 
ter sequestrado a menina) e também que Rial tinha de si mesma (pois prometeu cuidar de Nyagak no começo do filme e não conseguiu salvá-la), ao país de origem, para o qual, se voltarem, provavelmente irão morrer, e ao país de chegada, que não corresponde ao que esperavam na esfera do acolhimento. Esses são objetos perdidos com os quais ambos vão ter de lidar para poderem realizar o que lemos como trabalhos de luto ${ }^{24}$.

Voltando-nos, então, à dívida mencionada por Rial,

Lacan desloca as concepções sobre a relação de objeto para uma teoria sobre a falta deste (Peres, 2006). Para Lacan, o luto decorrente da perda do seio materno irá estruturar a condição desejante do sujeito, na medida em que "o desejo repousa sempre sobre uma falta, e o objeto se constitui sobre o vazio de um suposto objeto de satisfação plena” (Peres, 2006, p. 39) (SOUZA; PONTES, 2016, p. 72).

\section{E essa falta, seguem as autoras,}

diz respeito não apenas ao que faz falta, mas a uma culpabilidade originária e inconsciente, uma vez que o sujeito padece de uma culpa, como se ele fosse o responsável por sua perda. Essa autora aponta ainda que, para Lacan, essa culpa originária estaria relacionada ao gozo, sendo este aquilo que é excluído do simbólico. Nesse sentido, e em virtude do vazio dessa falta, o sujeito recorre ao significante, inserindo-se no universo simbólico (SOUZA; PONTES, 2016, p. 73).

Nesse contexto, seria a dívida apontada por Rial, então, relativa à uma idealização de que com um retorno de Nyagak todo o vazio e a exclusão sentidos por ela e seu marido no novo país, toda a dor associada aos processos de luto que competem entre si cessaria? Haveria uma expectativa por parte dela de uma tamponação ilusória do buraco no Real a partir da presença da criança enquanto objeto perdido? A falta de um significante nesse processo de luto que, segundo Lacan, "você não pode pagar a não ser com sua carne e com seu sangue" (LACAN, [1958-1959] 2002, p. 356), seria suprida ou melhor, paga, com o sacrifício de se deixar "comer" pelo apeth?

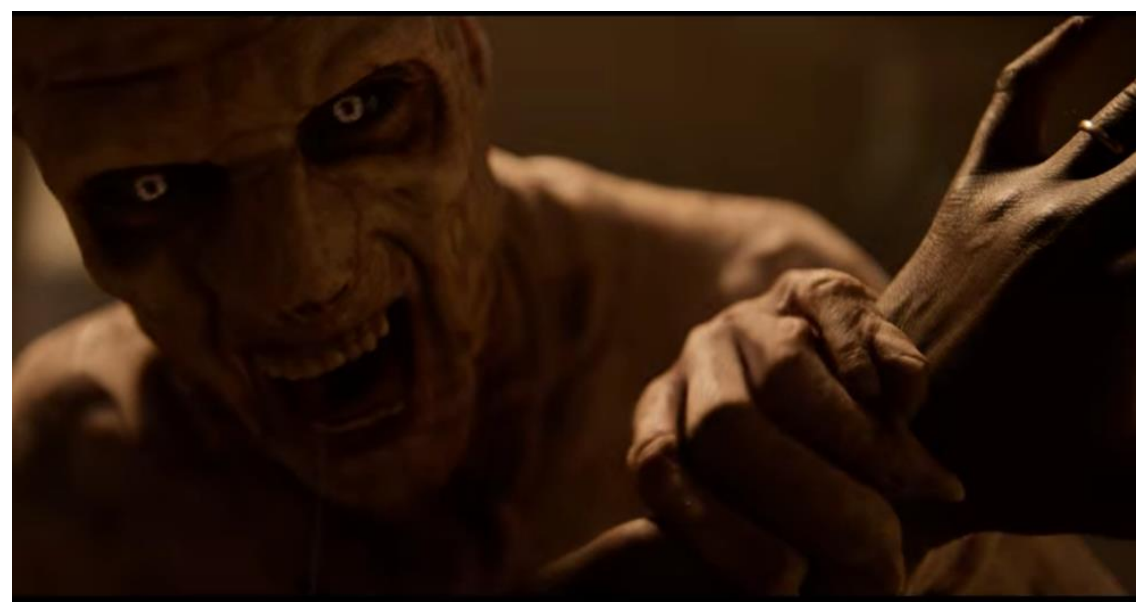

Figura 4: Apeth comendo Bol

Fonte: reprodução.

Perder o que nunca se teve, no caso, Nyagak, parece fazer com que - sem saber muito bem como lidar com os traumas que ela não cessa de não lembrar - Rial tenha atualizado uma forma que se coloca como "originária" de lidar com o luto (como o luto

\footnotetext{
${ }^{24}$ A opção por colocar trabalhos de luto no plural não vem para indicar que os processos são feitos separadamente, mas para reconhecer que são objetos perdidos diferentes. Da mesma forma, quando ficamos sabendo que o trauma da migração foi precedido por uma situação de extrema violência no Sudão do Sul, optamos por deixar de usar trauma no singular.
} 
do falo na castração, por exemplo ${ }^{25}$ ) para tentar dar conta de todas as perdas que sofreu em um curto espaço de tempo. Desse modo, assim como "[v]iver na linguagem [...] implica uma perda e é preciso consentir a ela para poder efetuar o trabalho de elaboração implicado no luto" (BESSET, 2007, s.p.), Rial parece atualizar essa perda, essa falta na dívida que imagina ter.

Ainda a respeito das formas diferentes de Rial e Bol fazerem os trabalhos de luto que enxergamos no filme, a forma como cada um lida com a morte de Nyagak, remetenos ao que Derrida ([1993] 1994) propõe acerca da espectralidade. Se empreendêssemos uma visão mais descolada do apeth a respeito desse trabalho subjetivo - que parece estar em curso nos protagonistas -, poderíamos interpretá-lo por duas chaves: da perpetuação do morto (feita por Rial) e da sentinela para que o morto não volte (feita por Bol), visto que ambos os processos mantêm o morto "vivo", em um trabalho que não é de qualquer ordem, mas "o trabalho mesmo", uma "produção" (DERRIDA, [1993] 1994, p. 134). Nessa tarefa que, para Derrida ([1993] 1994) e à contrapelo de Freud, é interminável, "os vivos mantêm os mortos, ocupam-se deles, agem como eles; são mantidos ocupados e agidos pelos mortos, falam-nos e falam-lhes, portam seu nome e conservam sua linguagem" (DERRIDA, [1993] 1994, p. 155). A partir dessa visada, teríamos dois caminhos para fazer o trabalho de luto: enterrar o corpo e vigiá-lo para que o morto não volte (o que lemos no personagem de Bol) ou fazer o possível para ele não caia no esquecimento (o que lemos no personagem de Rial).

Isso leva-nos à continuação do diálogo de Rial e Bol sobre o apeth, em que, perante a promessa do bruxo da noite de que seria possível trazer Nyagak de volta, eles discutem e ela afirma, em dinka, que a criança está viva, enquanto Bol, em inglês, diz que ela está morta. Ao recusar-se a falar a língua-cultura inglesa, como exigido pelo marido nessa cena, declarando que iria falar a língua de sua mãe ${ }^{26}$, Rial parece negar-se não só a se implicar na cultura do outro, mas também a se desvencilhar da língua da menina que eles haviam sequestrado e de tudo o que está atrelado, para ela, à língua-cultura dinka. Essa resistência de Rial ao inglês, em alguns momentos, parece nos remeter a uma rejeição ao esquecimento de Nyagak,

[à] apropriação viva do espírito, [à] assimilação de uma nova língua, [que] já se trata de uma herança. [...] Essa herança revolucionária supõe, decerto, que se acabe por esquecer o espectro, o da língua primitiva ou materna. Não para esquecer o que se herdou, mas pela pré-herança a partir de que herda. Esse esquecimento não é nada além de um esquecimento. Pois o que se tem de esquecer terá sido indispensável (DERRIDA, [1993] 1994, p. 151).

Por sua vez, a forma como Bol se coloca em relação ao país de (des)acolhimento é de querer, sempre que possível, ser como um homem inglês, comprar as roupas que eles usam, comer usando talheres - o que é repreendido por Rial que diz sentir apenas o gosto do metal - e até cantar canções locais em busca de ser reconhecido pelo outro e de estabelecer um laço social com aquele povo/país. Porém, "ao se precipitar em um contexto onde se deve falar a língua do outro, o sujeito migrante se encontr[a] em um dramático entre-duas-línguas, perto da materialidade da palavra, porém longe do sentido" (AYOUCH, 2015, p. 98, grifo nosso), reavivando o trauma, o corte imposto por sua vivência de migração. Nesse sentido, o migrante precipita-se, a nosso ver, tanto por antecipar sua inserção na língua - mas, afinal, existe um momento em que se está pronto

\footnotetext{
${ }^{25}$ Trazemos esse exemplo apenas a título de ilustração da proposição psicanalítica lacaniana e não como forma de afirmar que a castração, caso ocorra, se dá da mesma forma tanto numa interpretação ocidental do inconsciente quanto em outras possíveis leituras, como nos povos africanos por exemplo. Uma obra que traz apontamentos interessantes sobre esse tema é Édipo Africano (ORTIGUES; ORTIGUES, 1989).

26 “I will speak my mother's language".
} 
a falar uma outra língua? - quanto por se colocar perante o precipício do outro, tão dessemelhante, porém necessário para reestabelecer a dimensão da alteridade.

Ademais, "[n]este trabalho do luto em andamento, nesta tarefa interminável, o fantasma vem a ser o que mais dá a pensar - e a fazer. Insistamos e precisemos: a fazer acontecer, assim como a deixar acontecer" (DERRIDA, [1993] 1994, p. 135). Esses fantasmas, que "também falam línguas diferentes" (DERRIDA, [1993] 1994, p. 132), aparecem no filme em um crescente, desafiando a percepção do casal do que é real e do que é ilusão, do que pode, de fato, tocá-los e feri-los e o que fará isso apenas em seus sonhos - por mais devastadores que sejam. Nesse sentido, Derrida ([1993] 1994) excede essa figura indo em direção ao que propõe como espectralidade, que é produtiva e "diz respeito [...] a tudo que eu chamo de lógica espectral, aquilo que, na nossa experiência, não é nem inteligível, nem sensível, nem visível, nem invisível e que tanto diz respeito à linguagem quanto à telecomunicação" (MILLAN; DERRIDA, 1994). Ainda, essa (in)visibilidade do espectro vai "além do fenômeno ou do ente", sendo ele também "o que se imagina, o que se acredita ver e que é projetado" (DERRIDA, [1993] 1994, p. 138), "nunca acontece[ndo] sem angústia", "sem um movimento de repulsa ou de restrição" (DERRIDA, [1993] 1994, p. 148). Assim,

[a] conjuração [dos espectros] não está somente caracterizada; ela não se deixa determinar por acréscimo de uma certa angústia [...]; ela está destinada à angústia que ela é. A conjuração é angústia a partir do momento em que invoca a morte para inventar o vivo e fazer vivo o novo, para fazer vir à presença o que ainda não esteve aí (DERRIDA, [1993] 1994, p. 148, grifos do autor).

Essa angústia, à qual podemos nos voltar a partir da culpa originária com Lacan (SOUZA; PONTES, 2016) ou a partir do Unheimlich (incômodo) de Freud ([1919] 2021), parece se referir "à irrupção do estrangeiro no interior do familiar, mas também do animado no inanimado, do vivo no morto, do animismo no interior do totemismo, de imagens narcísicas em uma organização que já as devia ter superado (Dunker, 2019)" (KANTZ; DUNKER, 2020, p. 42). Nessa dimensão, somos levados a nos remeter à casa da qual o apeth se apossa e que, como já mencionado, torna-se também um personagem, acompanhando o desenrolar dos ânimos dos protagonistas, principalmente de Bol, e se "esburacando", se desmontando enquanto olha para o casal que nela habita. Assim, tal qual nos aponta Derrida ([1993] 1994),

\footnotetext{
o espectro primeiramente nos vê. Do outro lado do olho, efeito de viseira, ele nos olha antes mesmo que o vejamos ou que não vejamos simplesmente. Sentimo-nos observados, às vezes vigiados por ele, antes mesmo de qualquer aparecimento. Sobretudo, e eis aí o acontecimento, pois o espectro pertence ao acontecimento, ele nos vê por ocasião de uma visita. Ele nos visita. Uma visita atrás da outra, visto que ele volta para nos ver e que visitare, frequentativo de visere (ver, examinar, contemplar), traduz bem a recorrência ou a reaparição, a frequência de uma visitação (DERRIDA, [1993] 1994, p. 138-139).
}

Além da dimensão do olhar ser muito importante para os Dinka (LIENHARDT, 1951), no filme mesmo podemos observar momentos em que ambos encaram de volta o que os olha de dentro das paredes da casa, ou do fora, a depender da perspectiva. Nesse aspecto, Freud ([1919] 2021) menciona que "[p]ara muitas pessoas, parece incômodo no mais alto grau aquilo que se relaciona com a morte, com cadáveres e com o retorno dos mortos, com espíritos e fantasmas" (FREUD, [1919] 2021, p. 94), sendo a tradução de "uma casa Unheimlich" muitas vezes feita como "uma casa mal-assombrada". 


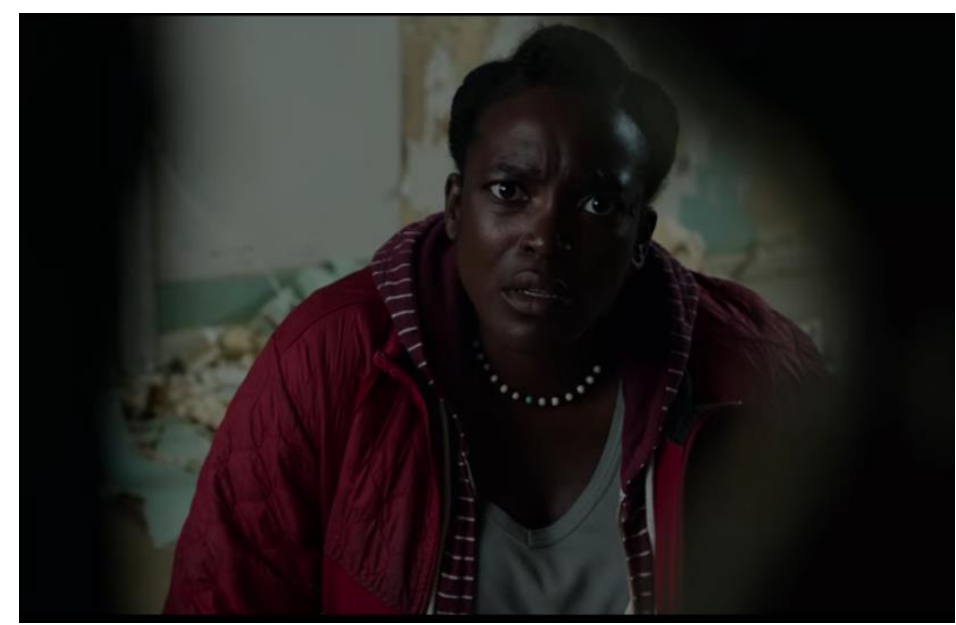

Figura 5: Rial olha de volta para o que a encara de dentro-fora da parede Fonte: reprodução.

Vinculada ao caráter disruptivo dos filmes de terror ${ }^{27}$, no que se refere à narrativa, é interessante pontuar também a interpretação de Lacan sobre o Unheimlich:

"[s]úbito", "de repente" — vocês sempre encontrarão essas expressões no momento da entrada do fenômeno do unheimlich. Encontrarão sempre em sua dimensão própria a cena que se propõe, e que permite que surja aquilo que, no mundo, não pode ser dito (LACAN, [1962-1963] 2005, p. 86 , grifos do autor).

Isso que não pode ser dito é retomado por ele no encontro seguinte desse seminário, quando aponta que não há os mesmos recursos em todas as línguas para dizer o que quer que seja - reiterando o caráter da perspectiva transcultural como relevante para pensarmos casos como esse. Nesse sentido, considerando que Lacan compreende o trabalho de luto justamente como um buraco no Real provocado pela perda que se mostra como (não) lugar do significante que falta, seria aí que o "fenômeno do luto" (LACAN, [1958-1959] 2002, p. 356) se encontraria com o Unheimlich, na dimensão simbólica da "loucura compartilhada" (LACAN, [1958-1959] 2002, p. 356) da cultura dinka. Acerca desse incômodo, Freud ([1919] 2021, p. 48) ainda afirma que "[n]ão há dúvida de que ele figure entre o que é aterrador, que suscita medo e horror, assim como também é certo que essa palavra nem sempre é utilizada num sentido que se possa determinar com precisão e acabe por coincidir com aquilo que suscita medo", impregnado nos personagens e na proposta geral do filme.

Por fim, entre o horror e a angústia, a realidade assume um papel importante, pois enquanto o horripilante, como apontado por Freud ([1919] 2021, p. 106, grifos nosso), "[t]rata-se aqui, portanto, puramente de uma questão de teste de realidade; de uma problemática de realidade material", o próprio trabalho do luto também pode ser visto como "concluído [numa perspectiva freudiana] quando a realidade prevalece e quando, atingido certo grau de catexia, a libido é desligada e o ego se vê livre e desinibido outra vez" (CAVALCANTI et. al, 2013, p. 95, grifo nosso). Assim, ainda que as concepções realidade e fantasia dependam, como vimos, das possibilidades de simbolização ligadas a determinadas línguas-culturas, é a partir das verdades constituídas por e a partir delas que os trabalhos de luto por nós observados lidam com o que (não) fica para trás.

\footnotetext{
${ }^{27}$ Há um artigo sobre a relação entre o luto e o terror em obras fílmicas escrito por Ribeiro et al. (2018).
} 


\section{ALGUMAS (DES)AMARRAÇÕES}

Bem como o característico susto provocado por filmes de terror, "a experiência e o ato de luto abrem por inteiro uma questão que não é de realidade, mas de verdade" (RIBEIRO et. al, 2018, p. 338), ou seja, do que é produzido enquanto verdade e que pode ser visto como uma possível amarração simbólica para dar contorno ao sem sentido. Assim, para além da Unheimlich, na dimensão do horror no luto atualizam-se as feridas traumáticas e as maneiras como a elas reagimos.

Quando isso se dá em situações de migração forçada, em primeiro lugar impõemse aspectos culturais e experiências de estrangeiridade (KANTZ; DUNKER, 2020, p. 29) que se colocam como formas de angústia, podendo ser agrupadas em: "o que devia ficar oculto, mas aparece revelado; o corpo morto que adquire vida; o corpo vivo que é experimentado como coisa; a casa íntima e acolhedora onde emerge o mais radical estranho, o parado imóvel que ainda assim se mostra animado" (KANTZ; DUNKER, 2020 , p. 29) e que parecem se repetir mesmo em contextos muitos diversos.

Em segundo lugar, a forma como a travessia foi feita - muitas vezes assustadoramente - e o que levou o sujeito migrante a sair de seu país de origem geralmente situações horripilantes - são sempre colocados em jogo, ampliando essa dimensão para o (des)acolhimento, para a (im)possibilidade de (re)construção do laço social, colocando mais uma vez o sujeito em situações de violência que também são da ordem do sem sentido. Por sua vez, do lado do "cidadão", do "nacional" que recebe essas pessoas, parece haver, em contraponto ao furo no Real (ou luto) ocasionado pela perda, um

excesso de real [que] marca um sujeito que muitas vezes aparece condenado a uma dessubjetivação operada pelo Outro mortífero, que goza na submissão enquanto sujeito, a eventos potencialmente traumáticos e em experiências que o colocam no lugar da abjeção (BINKOWSKI; BERRIEL, 2018, p. 94).

Flertando com sua própria possibilidade de dessubjetivação, o "nacional" que patologiza o luto do "estrangeiro" ou qualquer diferença mais pronunciada, também tem suas feridas atualizadas perante o horror - que ganha contorno no corpo do outro - de seu próprio e hipotético destino. Sujeitos como Rial e Bol trazem consigo a ameaça dos trabalhos de luto que não se referem à perda de um ente, mas, sim, de sua própria semelhança (imaginada) à alteridade ideal.

O que ficou para trás (2020), filme aqui analisado, se enquadra no gênero horror e isso, a nosso ver, pode se dar não só pela obviedade assustadora da figura encarnada do apeth como também pelo Unheimlich do trabalho de luto e pelo caráter abjeto que Rial e Bol ganham ao decorrer da trama perante os ingleses - o que ocorre com muitos migrantes e outros sujeitos marginalizados. Ademais, a presença dos marginalizados, sejam eles migrantes, pobres, ou outros grupos minoritarizados, assusta, ao carregarem consigo um ensaio ficcional de nosso próprio destino.

Lançado via streaming um dia antes do Halloween, o longa dispõe da figura do apeth para compor as cenas mais assustadoras, que termina, como é comum em filmes desse gênero, sendo morta por Rial para salvar Bol. Isso é feito logo após a rememoração de Rial dos eventos traumáticos tanto do homicídio de suas colegas quanto do sequestro e da morte de Nyagak, que retorna, nesse ponto, não mais como fantasma persecutório, mas como espectro do que viveram. Nesse sentido, mais uma vez voltamos à experiência do luto, pois ela "remonta sempre [...] a 'matar a morte' em nós: a traçar um limite entre o eu vivo e o morto, a fim de conseguir se separar do objeto perdido, introjetando-o, 
digerindo-o para melhor expulsá-lo" (ROGOZINSKI, 2015, p. 54). Não se trata, então, apenas da morte do monstro, mas de tudo aquilo que os acompanhava desde o Sudão.

Por fim, $O$ que ficou para trás (2020) traz em sua última cena a dimensão do "(não)" com a qual vimos jogando durante este artigo. No diálogo derradeiro, a resposta de Bol aos questionamentos de um dos agentes que cuidava de seu caso - em tom de deboche justamente por faltar uma perspectiva transcultural - quanto à presença do bruxo na casa e a uma suposta loucura que ele reconhecia no casal, parece sintetizar o fim do que interpretamos como trabalhos de luto no longa: "[s]eus fantasmas seguem você. Eles nunca se vão. Eles vivem com você. Quando eu os deixei entrar, pude começar a me encarar ${ }^{28} "$. Assim, a morte do luto simbolizada pela morte do apeth e a aceitação do que aconteceu - que também podemos ver como responsabilização quando Rial e Bol concordam em responder ao apeth e, por consequência, ao que fizeram, entregando o corpo de Bol - não fazem com que o objeto perdido fique para trás, esquecido para nunca mais ser lembrado, ao contrário do que poderia se pensar no senso comum. O que (não) fica para trás acompanha nossas outras perdas, nossos outros trabalhos de luto, (in)visivelmente, em uma presença-ausência espectral, constitutiva e inescapável. É com eles e a partir deles que podemos nos encarar, tentar nos haver com a falta e, por que não, desejar(,) futurar.

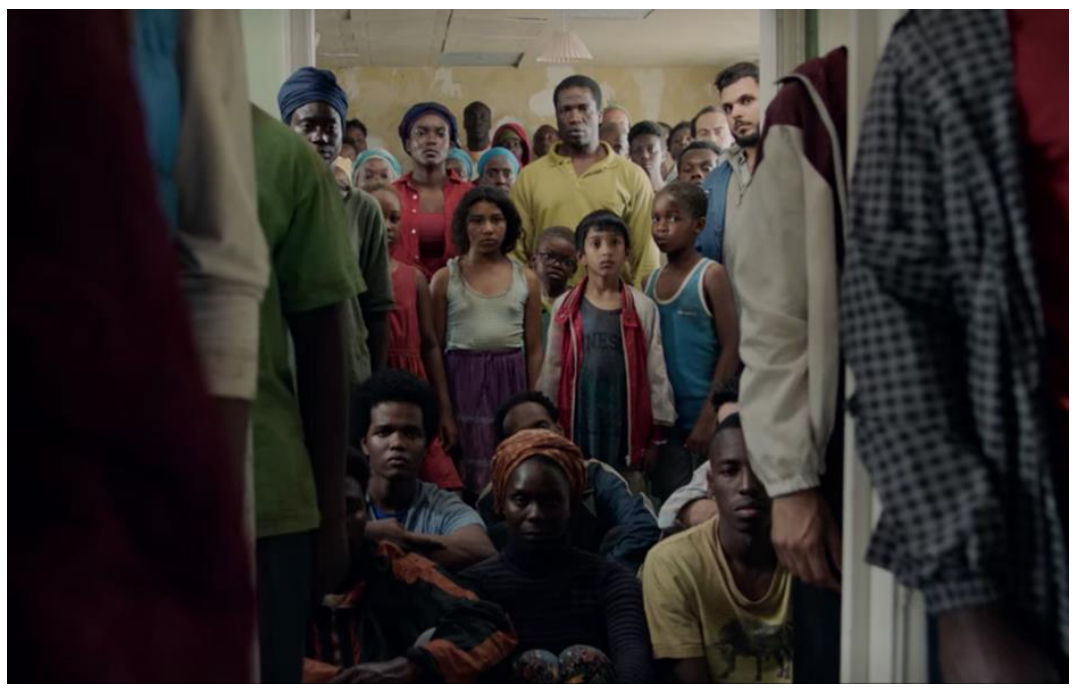

Figura 6: Bol, Rial e os Espectros

Fonte: reprodução.

\section{$\overline{\text { REFERÊNCIAS }}$}

AYOUCH, Thamy. Clínica psicanalítica da língua: vias associativas interlinguísticas, tradução e transferência. Estudos de Psicologia (Campinas), v. 32, n. 1, p. 97-107, 2015.

BESSET, Vera Lopes. Luto e angústia: questões em torno do objeto. Lat. Am. j. fundam. psychopathol. on line, São Paulo, v. 4, n. 2, p. 185-192, nov. 2007. Disponível em http://pepsic.bvsalud.org/scielo.php?script=sci_arttext\&pid=S1677$03582007000200006 \& \operatorname{lng}=$ pt\&nrm=iso. Acesso em 5 abr. 2021.

BINKOWSKI, Gabriel Inticher; BERRIEL, Nadia Jorge. ENREDANDO-SE PELAS TEIAS DO OUTRO: UM CASO NA CLÍNICA TRANSCULTURAL PSICANALÍTICA. Revista Acta Psicossomática, n. 1, p. 90-100, 2018.

BIRMAN, Joel; HOFFMANN, Christian. Lacan e Foucault: conjunções, disjunções e impasses. São Paulo: Instituto Langage/Université Paris Diderot, 2017.

28 "Your ghosts follow you. They never leave. They live with you. It's when I let them in, I could start to face myself". 
CAVALCANTI, Andressa Katherine Santos; SAMCZUK, Milena Lieto; BONFIM, Tânia Elena. O Conceito Psicanalítico do Luto: Uma Perspectiva a Partir de Freud e Klein. Psicólogo inFormação, v. 17, n. 17, p. 87-105, 2013.

CORACINI, Maria José Rodrigues Faria; CAVALLARI, Juliana Santana. Entremeios, Seção Entrevista, Programa de Pós-graduação em Ciências da Linguagem (PPGCL), Universidade do Vale do Sapucaí, Pouso Alegre (MG), vol. 13, p. 301-310, jul-dez, 2016.

CORACINI, Maria José. A perspectiva discursivo-desconstrutiva na pesquisa em Linguística Aplicada. In: SZUNDY, Paula T. C.; TILIO, Rogerio; VALIM de MELO, Glenda C. (orgs.): Inovações e desafios epistemológicos em Linguística Aplicada: perspectivas sul-americanas. Campinas (SP): Pontes, 2019.

DERRIDA, Jacques. "Fazer justiça a Freud": a história da loucura na era da psicanálise. In: ROUDINESCO, Elisabeth. Foucault: leituras da história da loucura. Trad. Maria Ignes Duque Estrada. Rio de Janeiro: Relume Dumará, (1992) 1994.

DERRIDA, Jacques. Espectros de Marx: o Estado da dívida, o trabalho do luto e a nova internacional. Trad. Anamaria Skinner. Rio de Janeiro: Relume Dumará, 1993.

DERRIDA, Jaques. Pour l'amour de Lacan. In: Résistances de la psychanalyse. Paris: Galilée, (1990) 1996.

DINIZ, Igor Mello. Os Dinka e nós, antropólogos: Controle da experiência e experiência etnográfica. Revista de Antropologia Social dos Alunos do PPGAS-UFSCar, v. 3, n. 1, p. 198-211, 2011.

FOUCAULT, Michel. Arqueologia do saber. Trad. Luiz Felipe Baeta Neves. $7^{\mathrm{a}}$ edição. Rio de Janeiro: Forense Universitária, (1969) 2008.

FREUD, Sigmund. Luto e melancolia. In: FREUD, Sigmund. Obras psicológicas completas de Sigmund Freud. Edição standard brasileira das obras completas. Vol. XIV. Rio de Janeiro: Imago, (1917) 1996.

FREUD, Sigmund. O incômodo. Trad. Paulo Sérgio de Souza Jr. São Paulo: Blucher, (1919) 2021.

IACONELLI, Vera. Luto insólito, desmentido e trauma: clínica psicanalítica com mães de bebês. Revista Latinoamericana de Psicopatologia Fundamental, v. 10, n. 4, p. 614-623, 2007.

KANTZ, Ilana; DUNKER, Christian Ingo Lenz. Clínica do cuidado: Estrangeiridade, estrangeiro e estranhamento. Calibán - RLP, v. 18, n. 1, p. 38-59, 2020.

LACAN, Jacques. O seminário, livro 10: angústia. Texto estabelecido por Jacques-Alain Miller. Versão final Angelina Harari. Preparação de texto: André Telles. Trad. Vera Ribeiro. Rio de Janeiro: Jorge Zahar Ed., (1962-1963) 2005.

LACAN, Jacques. O seminário, livro 6: o desejo e sua interpretação. Trad. Associação Psicanalítica de Porto Alegre a partir do texto estabelecido pela Association Freudienne, (1958-1959) 2002.

LIENHARDT, Godfrey. Some Notions of Witchcraft among the Dinka. Africa, v. 21, n. 4, p. 303-318, 1951.

LIENHARDT, Godfrey. The Situation of Death: An Aspect of Anuak Philosophy. Anthropological Quarterly, v. 35, n. 2, p. 74, 1962.

MAJOR, René. Lacan com Derrida. Trad. Fernanda Abreu. Rio de Janeiro: Civilização Brasileira, 2002.

MILLAN, Betty; DERRIDA, Jacques. Derrida caça os fantasmas de Marx. Folha de S.Paulo, Paris, 26 jun. 1994. Disponível em: https://www1.folha.uol.com.br/fsp/1994/ 6/26/mais!/24.html. Acesso em: 3 abr. 2021.

MORO, Marie Rose. Psicoterapia transcultural da migração. Psicologia USP, Trad. Viviani do Carmo Huerta. v. 26, n. 2, p. 186-192, 2015.

O QUE FICOU PARA TRÁS. Direção de Remy Weekes. Londres: Regency Enterprizes, BBC Films, Vertigo Entertainment, Starchild Pictures: 2020. Distribuído por Netflix.

ORTIGUES, Marie-Cécile; ORTIGUES, Edmond. Édipo africano. Trad. Claudia Berliner. São Paulo: Escuta, 1989.

RIBEIRO, Thales de Medeiros; RIBEIRO, Karine de Medeiros; NASCIMENTO, Elisa Mara do; FERNANDES, Leonardo Paiva. Luto e terror: lado a/lado b. REVISTA DE LETRAS - JUÇARA, v. 2, n. 1, p. 332-352, 2018.

ROGOZINSKI, Jacob. Defunta morte: luto, sobrevida, ressurreição. Alea: Estudos Neolatinos, v. 17, n. 1, p. 52-63, 2015.

ROSA, Marluza Terezinha da; RONDELLI, Daniella Rubbo Rodrigues; PEIXOTO, Mariana Rafaela Batista Silva. Discurso, Desconstrução e Psicanálise no campo da Linguística Aplicada: (du)elos e (des)caminhos. DELTA, São Paulo, v. 31, pp. 253-281, ago 2015. Disponível em: http://www.scielo.br/scielo.php?script=sci_arttext\&amp; 44502015000300011\&amp;lng=pt\&amp;nrm=iso. Acesso em jul. 2021.

SAAL, Frida. Lacan à Derrida. 10 o Colóquio da Fundação Mexicana de Psicanálise. Tradução Sérgio Telles. $\quad 1994 . \quad$ Disponível em: $\quad$ http://revistapercurso.uol.com.br/index. php?apg=artigo_view\&ida=325\&ori=autor\&letra=S. Acesso em maio 2021. 
SOUZA, Andressa Mayara Silva; PONTES, Suely Aires. As diversas faces da perda: o luto para a psicanálise. Analytica, v. 5, n. 9, p. 69-85, 2016.

Recebido: 6/4/2021

Aceito: 25/9/2021

Publicado: 25/11/2021 